\title{
Application of active learning techniques on Electrical Machines course in classroom environment: pedagogical strategy and results
}

\author{
S. Rafael and J. Justino \\ Setúbal School of Technology \\ Polytechnic Institute of Setúbal \\ Setúbal, Portugal \\ silviano.rafael@estsetubal.ips.pt
}

\begin{abstract}
In this paper the pedagogical experience in the implementation of the learner-centred approach on the course unit Electrical Machines of the final year of an engineering degree is presented. The learning techniques, the learning and teaching activities developed and the evaluation method used are depicted, as well as some of the results of the surveys carried out on students for which a summary analysis is conducted and some of its consequences are presented. Moreover, the academic performance from the last four academic years is considered within the pedagogical methodologies applied.
\end{abstract} group.

Keywords-active learning strategies, collaborative working

\section{INTRODUCTION}

In the course unit Electrical Machines (EM), a course unit of the final year of an engineering degree, it has been applied, in previous academic years, the traditional teacher-centred approach. In this context, it is crucial, and increasingly necessary, to provide students with the work out and development of a wide range of competences, beyond the technical ones, so that students can be able to adjust to the modern economy needs [1]. However, the application of the traditional teacher-centred approach does not foster the students' key competences. Generally, there is little recognition of the importance of those competences to consciously turn them into learning outcomes of the several course units in an ongoing and structured way in most of Portuguese tertiary education, where teacher-centred approach still prevails [2]. These issues are not discussed systematically within faculty or in awareness-raising sessions organised by the departments' scientific teaching areas. In fact, the recognition of those competences, and their integration in the learning outcomes, would imply the implementation of a new pedagogical project based on the learner-centred approach. Aware of this problem, the entire pedagogical structure of EM was modified in order to implement the learner-centred approach. The main motivation of the application of this approach, from the teacher's point of view, is to contribute to their study by applying active learning techniques and investigating the importance of soft skills in academic performance as well as the deep learning of hard skills.

In addition to the objectives of the course unit, when implementing the learner-centred approach in the classroom environment, conditions were provided to the students in order to contribute to a more dynamic and committed learning, foster high performance, reduce the drop-out rate, contribute to the work out of critical thinking, promote the sharing of expertise by creating creative and critical environments and foster selfevaluation and self-criticism in a structured and careful way.

\section{RESEARCH Methodology}

Along the semester, two research methods were applied: a quantitative method and a qualitative method [3, 4]. These methods were sequentially or simultaneously applied according to issues raised and data to be evaluated.

In the quantitative method, based on students' investigations and assessments, two different surveys were carried out during the term time: initial and final. The initial survey, with multiple-choice questions, aimed to identify students' profile and some of their work or study preferences. This survey was carried out in the first class, before the start of academic work. The final survey, again with multiple-choice questions, sought to register the students' opinions regarding the initial objectives and their expectations on the learnercentred approach and to check how the change of methodology was perceived. All surveys were anonymous in order to protect the students' identity and privacy.

The qualitative method, based on the interpretative approach given by the teacher's personal observation in classes upon the students' behavioral attitude along the learning process, provided useful information about how the learning process was being conducted, interpreted and experienced, as well as additional information on the surveys' questions.

\section{Pedagogical Methodology}

There are several methodologies that could be applied, but not all of them would have been suitable for the classroom environment with the given objectives. Therefore, the learnercentred approach was considered the most appropriate. This approach implies a teacher's change of attitude and an ongoing reflection in the act of teaching and learning [5]. In this sense, it is the teacher's responsibility to construct the entire pedagogical structure and to design and establish the means and conditions of teaching, learning and assessing, according to a detailed planning duly aligned with the contents, and its 
degrees of depth, objectives and skills to be achieved. On the other hand, the student assumes the responsibility for his training, autonomy and personal development. During the class time the teacher assumes several roles such as the facilitator of the students' learning process, the observer of the students' cognitive and personal development, the analyst of the students' decisions, the manager of the topics and the depth which they need to be addressed, the assessor of the skills acquired and the supervisor and mediator in complex situations.

Furthermore, this approach allows readjustments and adaptations during term time, according to the needs or to behavioral or cognitive changes of the students not originally foreseen.

\section{Pedagogical Strategy ApPlied}

Throughout the learning activities the following training techniques were applied, depending on the learning outcomes, contents, students' skills to be developed, initial students' cognitive conditions and the available time to achieve the intended objectives, as in:

- Structured groups with hierarchical relationships: applied on the first half of the semester in simulations of actual work environment [6]. The group members assume real life roles from the workplace.

- Cooperative or collaborative learning groups: applied on the second half of the semester in order for students to work collaboratively by sharing cognitive skills, negotiating decisions with their peers and developing key competences [7].

- Just in time teaching: applied whenever the students expressed doubts about knowledge base, not about the new one [8].

- Flipped classroom: $[9,10,11]$ applied in an adapted way whenever time was not enough in the classroom in order to develop the research work and response study to questions and problems in another context. In the following class the discussion, leveling of knowledge and evaluation was made.

- Gallery walk: applied in an adapted way to speed up the learning process of a topic [12].

- Inquiring based learning: the most applied technique in the classroom [13]

- Problem-based learning: applied as a complement to inquiring based learning.

\section{LEARNING ACTIVITIES}

The learning activities were developed considering the objectives and the training technique to be used. Six learning activities were implemented over the semester according to the EM's topics, based on inquiring and problems. The conceptual and rational part was highlighted, relating the magnetic, electrical and mechanical phenomena to the laws, physical and mathematical models and operational rules. The learning activities provided opportunities for discussion among peers, individualized study, sharing of expertise, collaborative and reasoning work and validation of results.

\section{TEACHING ACTIVITIES}

It was necessary to develop some teaching activities, properly contextualized within EM's contents, to encourage students in the work out of "learning to learn" in relation to the critical thinking [14]. This pedagogical attitude increased the students' self-confidence and improved the confidence in their background knowledge as well as the awareness of the importance of the lack or incomplete consolidation of knowledge base when solving the issues raised in EM. This awareness promoted, in some cases, the dialogue between members of the group and, in others, the autonomous study. In addition, this pedagogical attitude also contributed positively to the self-esteem and also, by to the way that reasoning began to be expressed, depending on the interiorization of this concept relating to critical thinking.

The teaching activities were framed and adapted to the contents and learning outcomes and interconnected with the learning activities. The following teaching methods were used during classes:

- Interrogative method, the most used method, originated and shared by students and supplemented with additional questions raised by the teacher.

- Expositive method, always used in a short period of time and only for the more complex subjects from the point of view of the student, being interconnected with the interrogative method.

- Demonstrative method also interconnected with the interrogative method whenever possible.

\section{EVALUATION ACTIVITIES}

A method of evaluation of the group and individual performance was developed to assess the knowledge related to the EM's topics, analysing the depth of the absorbed concepts and the application of critical reasoning in extrapolation of knowledge. An evaluation activity was applied at the end of each learning activity through training tests and at the end of the chapter related to the study of a machine, a summative test was conducted. So, as a result of two machines studied during the semester, students carried out six training tests and two summative tests. This ongoing evaluation fulfilled the students' expectations. Moreover, from the point of view of the topics addressed, students were required to work out the critical sense harder than usual, keeping them continuously active and linked to the EM's subjects and forcing them to work out the selfanalysis and self-evaluation capabilities.

\section{ANALYSIS OF RESULTS}

From the analysis of the initial survey's responses carried out on students, the following data was established according to the subjects covered. The results obtained from each subject are coupled and some comments, along with qualitative information, are given bellow. 
a) About the students' attitude towards the study and preparation for the class or evaluation:

- $50 \%$ of the students revealed to study individually, $38 \%$ with a colleague and only $12 \%$ in group.

- Students stated not having the habit of preparing the topics addressed in class previously and in an ongoing way. However, $63 \%$ of the students indicated to conduct an initial reading now and then during the semester

- $63 \%$ of the students stated to often summarise the contents to study later, $31 \%$ to prepare themselves on a daily basis by frequent reviews and $6 \%$ of the students stated to study in the run-up to the evaluation.

This issue establishes the importance of the application of the collaborative learning group technique for it contributes positively to improve the acquisition and sharing of knowledge in group as well as the development of metacognition.

These results may have been established from the fact that students are not used to being proactive in preparing a first approach to contents, pointing out a passive attitude. Thus, there is the need to foster the autonomous work capacity through the collaborative learning group and the flipped classroom activities.

b) About the students' attitude in classroom and in sctutured working group:

- $56 \%$ of the students stated to be introverted and passive in classroom environment while $31 \%$ stated to be actively participate and $13 \%$ claim to be frequently distracted.

- $69 \%$ of the students stated to never have worked in a structured working group while the remaining 31\% stated that they did.

Again, the passivity in students' habits is reported owing to the excessive application of expositive method. Thus, there is the need to provide active learning pedagogical environments within the context of structured groups so that students may work out their soft skills. The origin of the students' distractions may be from boring topics or too much lecture classes, associated to a low motivation.

c) About the method of evaluation:

- All students preferred to be evaluated by intermediate tests. In addition, $69 \%$ of the students also suggested practical work, in classroom or at home, to be evaluated along with tests.

This information contributed in the formatting of the course unit's continuous assessment.

The initial survey's results aforementioned were integrated in the constructive pedagogical alignment of the course unit, already developed and ready to be applied, by adapting it into the students' expectations and thus contributing to its readjustment. It should be noted that this pedagogical alignment brings more flexibility into the techniques to be applied, by adapting them to new environments during term time.

d) About the performance of the collaborative working group and the support provided by its peers:

- All students considered that the group worked well. In particular, $69 \%$ stated that sometimes the work could have been better while $31 \%$ stated that it had always worked well.

- $46 \%$ of the students stated to always have felt supported by the remaining group members, $46 \%$ stated that that support was often felt and $8 \%$ of the students stated to rarely have felt supported by the remaining group members.

Considering that this was the first time those students worked together in all the teaching hours of the curricular unit, adaptation and friction within groups was expected to be due to the personal characteristics of each member.

e) About learning group or individual learning and whether they were encouraged or not to discuss the topics:

- $92 \%$ of the students stated to have learned more in group than individually and the remaining $8 \%$ would have learned more if taking part of another group.

- $\quad 92 \%$ of the students stated to be encouraged to share its knowledge and the knowledge related to the contents of the curricular unit and the remaining $8 \%$ considered that they were sometimes encouraged.

These results are quite significant since a large majority of the students demonstrates that the collaborative working group fostered knowledge acquisition, contributing to the development of key competences. Also, no student stated that he would have learned more individually.

f) About assessment and the difficulty in acquiring skills:

- All students stated that the method of evaluation was suitable.

- $92 \%$ of the students indicated that the continuous assessment process was absolutely clear and the remaining $8 \%$ stated that it was clear sometimes.

- All students stated to have felt some difficulties in achieving the curricular unit's competences.

As previously mentioned, the assessment was settled by mutual agreement and therefore meeting the students' expectations. Moreover, the difficulties experienced by students was provided by the fact that it was requested to reach the goal of the $80 \%$ of the curricular unit's competences on the training tests.

g) About the learning activities:

- All students recognized the importance of the learning activities in studying and contents understanding.

- $46 \%$ of the students considered that the learning activities' dynamics was always useful while the 
remaining $54 \%$ stated that the dynamics was sometimes useful to their learning.

- $85 \%$ of the students considered the time dedicated to the learning activities as enough while the remaining $15 \%$ would have needed more time.

- $\quad 23 \%$ of the students clearly perceived the objectives in each learning activity developed and the remaining $77 \%$ often understood it.

- $77 \%$ of the students classified the curricular unit's learning process applied as excellent or good and the remaining $23 \%$ as satisfactory.

These results are relevant because they reflect to some extent the fitness of learning activities and the importance of how they were planned, designed, applied and interpreted in order to provide students with the acquisition of the intended competencies. The dynamics of the activity is also framed by the several working patterns between group members and between groups.

In Fig. 1 below the success rate of the curricular unit is presented as a percentage in order to show its academic performance over the last four years.

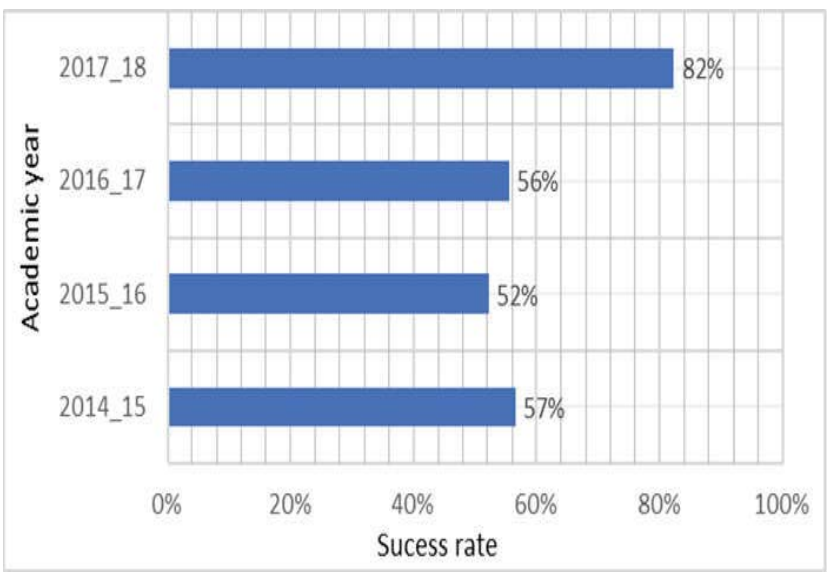

Fig. 1. Success rate over the last four academic years.

One can observe that the success rate on the academic years 201415,201516 and 201617 did not reach $60 \%$ while on 2017 - 18 the success rate was over $80 \%$. There is a significant increase of more than $20 \%$ on this last academic year where the learner-centred approach was applied for the first time.

On the first three academic years, from 2014 to 2017, the teacher-centred approach was the methodology applied, being the expository method the most often used in teaching activities. The evaluation method applied was split into two phases (in the middle and by the end of the semester) allowing students to study the topics in part. However, the academic performance did not improve, for the evaluation method is not the problem, it is how learning is carried out.

Thus, in the academic year of 2017_18 the learning process was actively carried out by students which led to more students reaching the course unit's objectives without outcomes' overvaluation, as some critics of the learner-centred approach would have us believe.

In Fig. 2 the percentage distribution of the scores obtained by students in the EM's course unit over the last four academic years is presented.

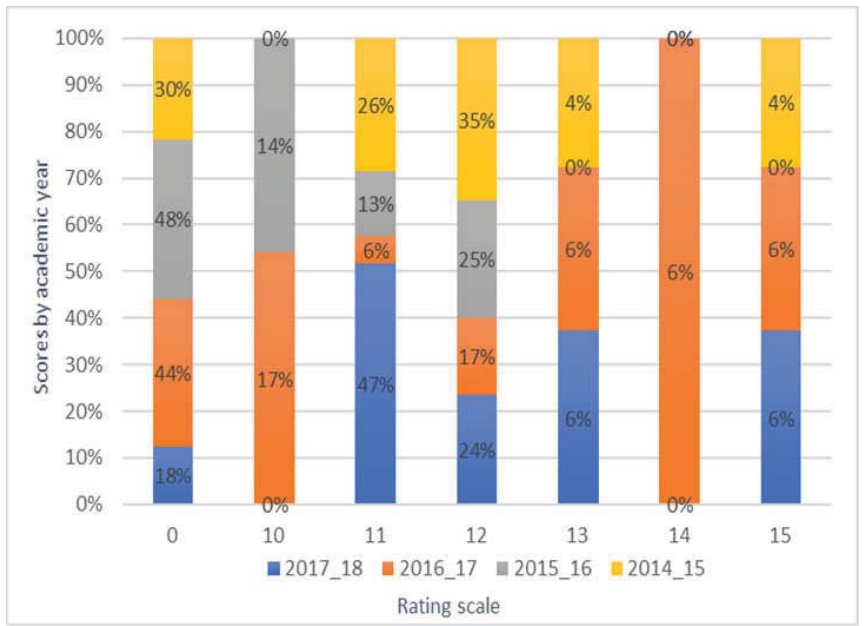

Fig. 2. Percentage outcomes of the scores obtained by students over the last four academic years.

Students that have failed the curricular unit, whether they attended classes or not, or by withdrawal, are included in this chart as scored zero values. It should be noted that in the academic year 2017_18 this percentage was the lowest of the four consecutive years under analysis. Although this situation may not be directly linked to the application of the learnercentred approach, it certainly contributed to be smaller.

It also should be noted that the percentage values for each score are not very wide, some even have the same rating scale like scores 13 and 15 .

\section{CONCLUSIONS}

The application of the learner-centred approach provides the active participation of the students which respects their cognitive, personal and self-realization construction. This active participation generates a teacher-student relationship of authenticity and congruence which contributes as a facilitator of the teaching-learning process.

Most of the students really appreciated the new methodology, showing more commitment and dedication during the learning activities. However, the best students may not appreciate this approach for reasons relating to personal characteristics as individualism and the feeling that they do not need their peers for their learning. In fact, these students may realise the collaborative working group as an additional effort because they must lead and drive the remaining group members. Moreover, students with learning skills gap by procrastination may also not appreciate this approach due to the accountability and pressure on by other group members.

It is essential to emphasize the importance of choosing and applying the appropriate pedagogical technique according to 
the objectives and the development needs of the students' skills in order to provide the necessary far-reaching and fruitful learning spaces.

\section{REFERENCES}

[1] C. C. Cardoso, C. Estêvão and P. Silva, "Competências transversais dos diplomados do Ensino Superior: perspectivas dos empregadores e diplomados", Final Report of the National Skills Task Force, London: DfEE, 2006.

[2] OECD, "Review of the tertiary education, research and innovation system in Portugal", Feb 2018, pp. 29, in press.

[3] A. Tashakkori and C. Teddlie, "Combining qualitative and quantitative approaches", Applied Social Research Methods Série, vol. 46, Thousand Oaks, CA: Sage Publications, 1998.

[4] D. W. Shaffer and R. C. Serlin, "What good are statistics that don't generalize?", American Educational Research Association, vol. 33, nº 9, 2004, pp. 14-25.

[5] J. Biggs and C. Tang, "Teaching for quality learning at university", McGraw -Hill/Open University Press/Society for Research into Higher Education, 4th ed., 2011.

[6] BCIT, "Effective use of group work", Learning and Teaching Centre of the British Columbia Institute of Technology, 2010.

[7] E. F. Barkley, K. P. Cross and C. H. Major, "Collaborative learning techniques: a handbook for college faculty", San Francisco; Jossey-Bass Publishers, 2014.

[8] A. Gavrin, "Just-in-Time teaching", Published in Metropolitan Universities, vol. 17, $\mathrm{n}^{\circ}$ 4, 2006, pp. 9-18.

[9] L. Betty, H. Angie, G. Neal and W. S. Andrew, "Student learning and perceptions in a flipped linear algebra course", International Journal of Matematical Education in Science and Technology, vol. 45, $\mathrm{n}^{\mathrm{o}} 3,2014$, pp. 317-324.

[10] Á. Fidalgo-Blanco, M. L. Sein-Echaluce and F. J. García-Peñalvo, "Ontological flip teaching: a flip teaching model based on knowledge management", Universal Access in the Information Society. In press. doi:10.1007/s10209-017-0556-6.

[11] Á. Fidalgo-Blanco, M. L. Sein-Echaluce and F. J. García-Peñalvo, "Flip teaching entre iguales peer to peer flip teaching", IV Congreso Internacional sobre Aprendizaje, Innovación y Competitividad (CINAIC 2017), doi:10.26754/CINAIC.2017.000001_129

[12] T. Hosseinali, "Teaching strategies for instructors", Lincoln Land Community College.

[13] P. Kahn and K. O'Rourke, "Understanding enquiry based learning", University of Manchester. Eds Galway: CELT, 2005.

[14] A. F. Peter, "Critical thinking: what it is and why it counts", Measured Reasons and the California Academic Press, 2011. 